\title{
Expression of vitamin D receptor in bronchial asthma and its bioinformatics prediction
}

\author{
LISHEN SHAN $^{1}$, XINYUAN KANG $^{2}$, FEN LIU $^{1}$, XUXU CAI $^{1}$, XIAOHUA HAN $^{1}$ and YUNXIAO SHANG ${ }^{1}$ \\ ${ }^{1}$ Department of Pediatric Pulmonology, Shengjing Hospital Affiliated to China Medical University, \\ Shenyang, Liaoning 110004; ${ }^{2}$ Department of Orthopedics, Shengjing Hospital Affiliated to \\ China Medical University, Shenyang, Liaoning 110122, P.R. China
}

Received October 8, 2017; Accepted December 14, 2017

DOI: $10.3892 / \mathrm{mmr} .2018 .9157$

\begin{abstract}
Vitamin D receptors (VDRs) are associated with the occurrence and development of asthma. The aim of the present study was to analyze the secondary structure and B-cell and T-cell epitopes of VDR using online prediction software and aid in the future development of a highly efficient epitope-based vaccine against asthma. Blood samples were collected from peripheral blood of asthmatic children. Reverse transcription quantitative-polymerase chain reaction (RT-qPCR) was performed to detect the expression of VDR in the peripheral blood. Mouse models of asthma were established. Hematoxylin and eosin staining was performed to observe the pathological alterations of the lungs of mice. Immunohistochemistry, western blot analysis and RT-qPCR were performed to detect the expression of VDR in the lungs of asthmatic mice. Online prediction software immune epitope database and analysis resource, SYFPEITHI and linear epitope prediction based on propensity scale and support vector machines were used to predict the B-cell and T-cell epitopes and the RasMol and 3DLigandSite were used to analyze the tertiary structure of VDR. RT-qPCR demonstrated that VDR expression in the peripheral blood of asthmatic children was decreased. Immunohistochemistry, western blotting and RT-qPCR demonstrated that VDR expression also decreased in the lungs of mouse models of asthma. VDR B-cell epitopes were identified at 37-45, 88-94, 123-131, 231-239, 286-294 and 342-350 positions of the amino acid sequence and VDR T-cell epitopes were identified at 125-130, 231-239 and 265-272 positions. A total of six B-cell epitopes and three T-cell epitopes for VDR were predicted by bioinformatics, which when validated, may in
\end{abstract}

Correspondence to: Dr Yunxiao Shang, Department of Pediatric Pulmonology, Shengjing Hospital Affiliated to China Medical University, 36 Sanhao Street, Shenyang, Liaoning 110004, P.R. China E-mail: shangyx@sj-hospital.org

Key words: asthma, vitamin D receptor, epitope, bioinformatics prediction the future aid in immunological diagnosis and development of a targeted drug therapy for clinical asthma.

\section{Introduction}

Bronchial asthma is a common respiratory disease and one of the most frequent chronic airway diseases to affect children (3-14 years) (1). Its incidence is increasing each year in China and it poses a mental and economic burden to patients and society (2). Bronchial asthma is an immunoglobulin (Ig)E-mediated type I chronic allergic disease that involves numerous inflammatory cells including eosinophils, mast cells, T cells and airway epithelial cells and can cause recurrent wheezing, shortness of breath, chest tightness or cough, and be life-threatening (3). The pathological mechanism of asthma is complex and associated with immunity and genetic background (4). The aims of asthma treatment include reducing the frequency of attacks, improving respiratory function preventing acute attacks and recurrent exacerbations and preventing death (5). Advances have been made in the control of symptoms of asthma, but the incidence of recurrent asthma remains high in China and the side effects associated with use of asthma drugs can be severe (6).

Vitamin D has been previously reported to serve a role in the pathogenesis of asthma (7). It was previously demonstrated to regulate bone metabolism and calcium balance (8). Increasing number of epidemiological, genetic and animal model studies have demonstrated that vitamin D exhibits strong immunoregulatory function and it is associated with innate and adaptive immune responses (9-13). Vitamin D receptor (VDR) is the main receptor for 1,25-hydroxy-vitamin D, the biologically active form vitamin D (14). Its polymorphism is closely associated with the occurrence of asthma in children and adults. In the present study, blood samples were collected from clinical patients with asthma and animal models of asthma were established to investigate the role of VDR in the disease in question. In addition, bioinformatics methods were used to predict the B-cell and T-cell epitopes of VDR and perform sequence analysis. The results of the present study provide theoretical data that can be further validated and in the future, may be used for prevention and treatment of asthma, and development of epitope-based vaccines against this disease. 


\section{Materials and methods}

Patients and groups. A total of 65 children with asthma (31 males, 34 females; average age $3.45 \pm 1.36$ years) who received treatment and 65 healthy children who acted as normal control (33 males, 32 females; aged $6.11 \pm 1.79$ years) in Shengjing hospital affiliated to China Medical University between March and June 2017, were included in the present study. The venous blood $(1 \mathrm{ml})$ was collected in children patients and the normal control group. The present study was approved by the Ethics Committee of Shengjing Hospital affiliated to the China Medical University (approval no. 2016PS86K). Inclusion criteria of these patients included: i) Recurrent wheezing, cough, breathlessness and chest tightness, all of which occurred due to contact with allergens, cold air, physical or chemical stimuli, respiratory infections and exercise, frequently worsening at night and/or in the early morning; ii) diffuse or scattered airflow limitation in both lungs mainly during the expiratory and prolonged expiratory phases; and iii) the above symptoms and signs were alleviated by anti-asthma treatment or self-mitigated. Exclusion criteria included wheezing, cough, breathlessness and chest tightness, caused by other diseases. Within 1 week prior to grouping, all patients did not use hormones or suffer from acute infection. The included patients were randomly divided into a normal control group (healthy children) and an asthma group (asthma children). Healthy children in the normal group received physical examination in Shengjing hospital and had no history of allergic diseases. All normal controls did not use hormone or suffer from acute infection within 1 week prior to grouping. Written informed consent was obtained from the guardians of the included children.

Animals and groups. Twenty BALB/c mice (6 weeks old, male, weight 20-23 g) were obtained from the Experimental Animal Center of China Medical University (Shenyang, China) [production license no. SCXK (Liao)-2016-2417; application license no. SYXK (Liao)-2016-2417]. Mice were given a normal diet and water and the housing conditions were as follows: Ambient temperature of $20-26^{\circ} \mathrm{C}, 40-70 \%$ relative humidity, $12-\mathrm{h}$ light/dark cycle. The present study was approved by the Animal Welfare and Ethics Committee of China Medical University Laboratory (Shenyang, China) (approval no. 2016072). Mice were randomly divided into two groups (according to random number table), including the control group $(\mathrm{n}=10)$ and asthma group $(\mathrm{n}=10)$.

Establishment of mouse models of asthma. Mouse models of asthma were established as previously described (15). On days 2, 8 and 15 , following the model establishment, model mice were sensitized by intraperitoneal injection of $0.2 \mathrm{ml}$ mixture of ovalbumin (OVA, 257-264, Sigma-Aldrich; Merck KGaA, Darmstadt, Germany) and aluminum hydroxide [2 $\mathrm{mg} / \mathrm{ml}$ OVA+0.1 $\mathrm{ml}$ aluminum hydroxide gel (1017502, Sigma-Aldrich; Merck KGaA)]. On the same days, equal amount of normal saline was intraperitoneally administered in normal control mice. On day 22, each mouse was placed in a 30x30x20 cm-sized closed container. Mice from the asthma group were sprayed with $2 \%$ OVA whereas mice from the normal control group were sprayed with normal saliva, once a day, 45 min each time, for 7 successive days. During this process, mouse behaviors and symptomatic reactions were closely monitored.

Sample collection. On day 29 following asthma induction, following anesthesia, mice were sacrificed with cervical prolapse and lung tissue was obtained, fixed with $10 \%$ formaldehyde at room temperature for at least $48 \mathrm{~h}$ and preserved at $-80^{\circ} \mathrm{C}$. Peripheral blood samples $(1 \mathrm{ml})$ were collected and preserved at $-80^{\circ} \mathrm{C}$.

Hematoxylin and eosin $(H \& E)$ staining. The aforementioned $10 \%$ formaldehyde-fixed, mouse lung tissue was placed in xylene for $10 \mathrm{~min}$, dehydrated in gradient ethanol (absolute, 95 and $75 \%$ ethanol) and infiltrated into paraffin liquid at $65^{\circ} \mathrm{C}$ for $1-2 \mathrm{~h}$, and paraffin-embedded and sliced into $5-\mu \mathrm{m}$ thick sections. Paraffin sections were dewaxed, stained with hematoxylin for $5 \mathrm{~min}$ at room temperature, PBS washed, differentiated with $1 \%$ hydrochloric acid-ethanol, stained with eosin for $1 \mathrm{~min}$ at room temperature and mounted with $40 \%$ neutral resin at room temperature. Finally, pathological alterations of lung tissue were observed under the light microscope (NE950, Leica Microsystems, Ltd., Milton Kaynes, UK).

Western blot assay. Lung tissues were triturated and lysed using radioimmunoprecipitation assay lysis (89900, Thermo Fisher Scientific, Inc., Waltham, MA, USA) buffer containing protease inhibitor for $30 \mathrm{~min}$ on ice, and 4,000 x g, centrifuged for $10 \mathrm{~min}$ at $4^{\circ} \mathrm{C}$, and the supernatant was collected. Protein concentration was determined using a BCA protein assay. Protein samples were subjected to $10 \%$ SDS-PAGE and transferred to a polyvinylidene fluoride membrane. The membrane was blocked by 5\% skim milk for $2 \mathrm{~h}$ and incubated overnight at $4^{\circ} \mathrm{C}$ with VDR antibody $(1: 1,000$; cat. no. ab109234; Abcam, Cambridge, UK) and GAPDH antibody $(1: 2,000$; cat. no. ab8245; Abcam). Following addition of horseradish peroxidase-labeled secondary antibody (goat anti-rabbit IgG/HRP antibody, 1:2,000, cat. no. bs-0295G-HRP, Bioss, Beijing, China), protein samples were incubated at room temperature for $2 \mathrm{~h}$. Protein bands were visualized using an enhanced chemiluminescence detection kit (32209, Thermo Fisher Scientific, Inc.) and a gel imaging system. Absorbance analysis was performed using Image J software (Image J 1.8.0, National Institutes of Health, Bethesda, MD, USA).

Reverse transcription-quantitative polymerase chain reaction $(R T-q P C R)$. Mouse lung tissues were harvested. Total RNA was extracted using TRIzol reagent (Thermo Fisher Scientific, Inc., Waltham, MA, USA), dried by sedimentation and incubated with $50 \mu$ l diethylpyrocarbonate-treated water. RNA purity and concentration were determined using an ultraviolet spectrophotometer. Total RNA was reserve transcribed into cDNA using the High-Capacity RNA-to-cDNA ${ }^{\mathrm{TM}}$ kit (K1266, Invitrogen; Thermo Fisher Scientific, Inc.). According to the manufacturer's protocol of the RT-qPCR kit (Qiagen GmbH, Hilden, Germany), VDR expression was detected. RNA primers were synthesized by Invitrogen (Thermo Fisher Scientific, Inc.). The following primer sequences were used for the PCR: VDR forward, 5'-GTAAGTACAGGGAGCTATT-3' and reverse, 5'-GATCTGAATGAAGAAGGCT-3'; GAPDH forward, 

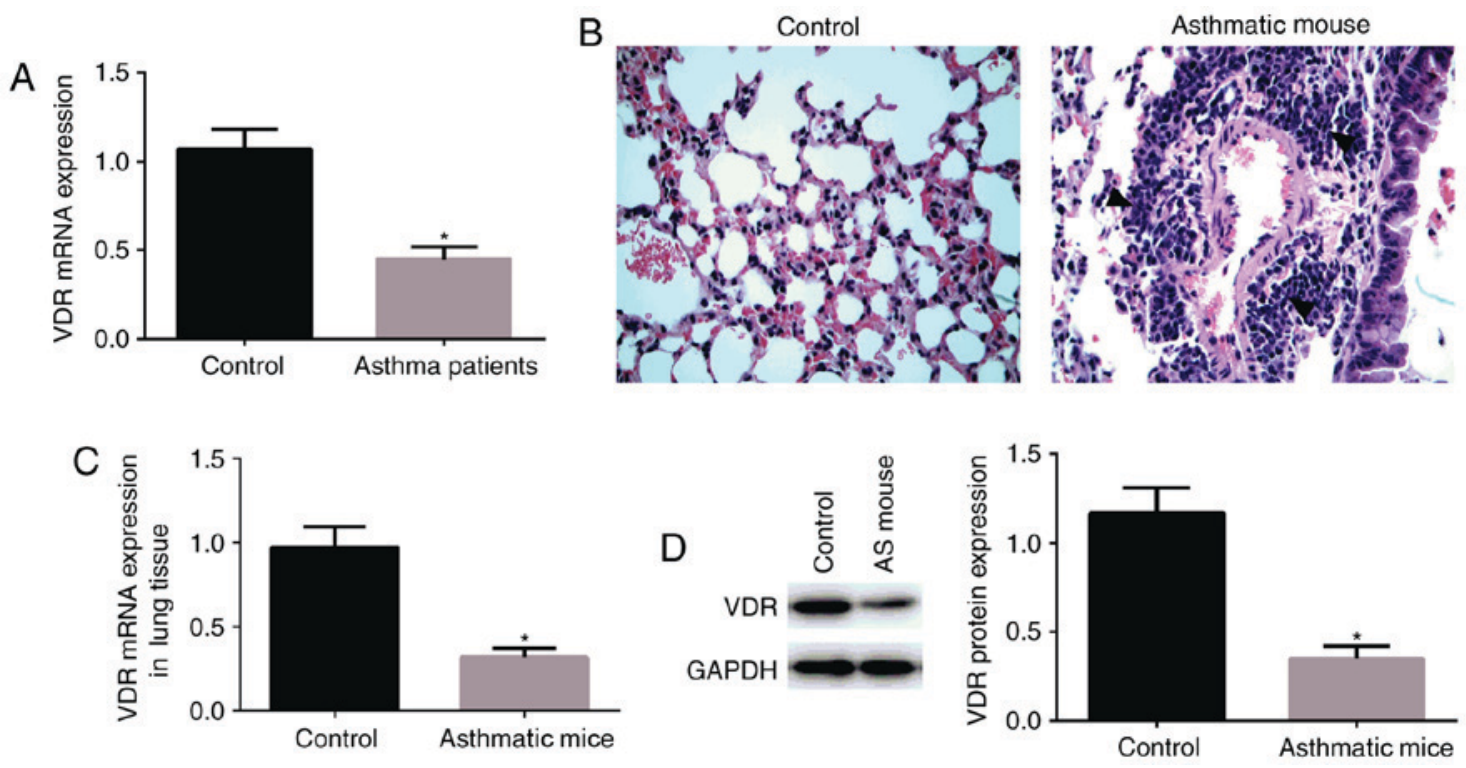

Figure 1. VDR expression in patients and mice. (A) VDR mRNA expression levels in human patients. (B) Pathological observation of bronchial lung tissue in mice by hematoxylin and eosin staining. Inflammatory cells were marked with an arrow. The pulmonary bronchial vessels, pulmonary interstitium and pulmonary alveolar cavity were not shown. Data collected from the control and asthma groups (magnification, x40). (C) VDR mRNA expression levels in mice. (D) Western blot assay was used to detect VDR protein expression in the bronchial lung tissue. " $\mathrm{P}<0.05$ vs. the control group. VDR, vitamin $\mathrm{D}$ receptor; AS, asthma.

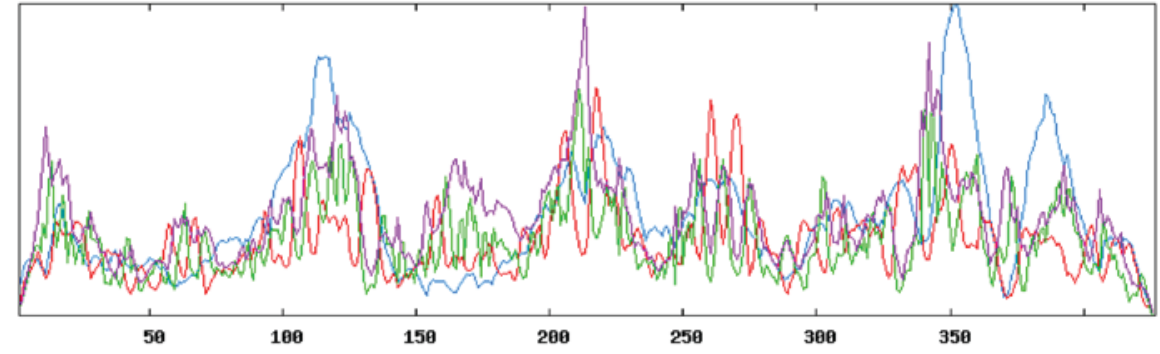
SOPMA:
Alpha helix
$3_{10}$ helix
(Hh) : 167 is $39.11 \%$
Pi helix
(Gg): $\quad 0$ is $0.00 \%$
Beta bridge
(li) : $\quad 0$ is $0.00 \%$
Extended strand (Ee) : $\quad 66$ is $15.46 \%$
(Bb) : $\quad 0$ is $0.00 \%$
Beta turn
(Tt) :
37 is $8.67 \%$
Bend region
(Ss) :
0 is $0.00 \%$
Random coil
(Cc) :
Ambiguous states (?) :
157 is $36.77 \%$
Other states
0 is $\mathbf{0 . 0 0 \%}$
0 is $0.00 \%$

Figure 2. Prediction of the components of the secondary structure of the protein encoded by vitamin D receptor gene. The predictions were made using SOPMA software.

\section{5'-AAGATCGAGAATTGACA-3' and reverse, 5'-GTCGGT GTGAACGGATTTG-3'.}

Protein secondary structure prediction in silico. Secondary structure of VDR (genbank ID: NM_009504.4) was predicted using Self-Optimized Prediction Method with Alignment (SOPMA) tool (npsa-prabi.ibcp.fr/cgi-bin/npsa_automat. pl?page=npsa_sopma.html).

B-cell epitope prediction. The online prediction resources, including immune epitope database and analysis resource
(IEDB; tools.iedb.org/bcell/) and linear epitope prediction based on propensity scale and support vector machines (LEPS) (leps.cs.ntou.edu.tw/index.php) together with hydrophilicity, antigenicity index, and flexibility parameters, as provided by the prediction websites, were used to predict B-cell epitopes. This online prediction software gives the amino acid sequence that may form the epitope.

T-cell epitope prediction. The online prediction resources SYFPEITHI (www.syfpeithi.de) and IEDB (tools.iedb.org/mhci/) were used to predict major 

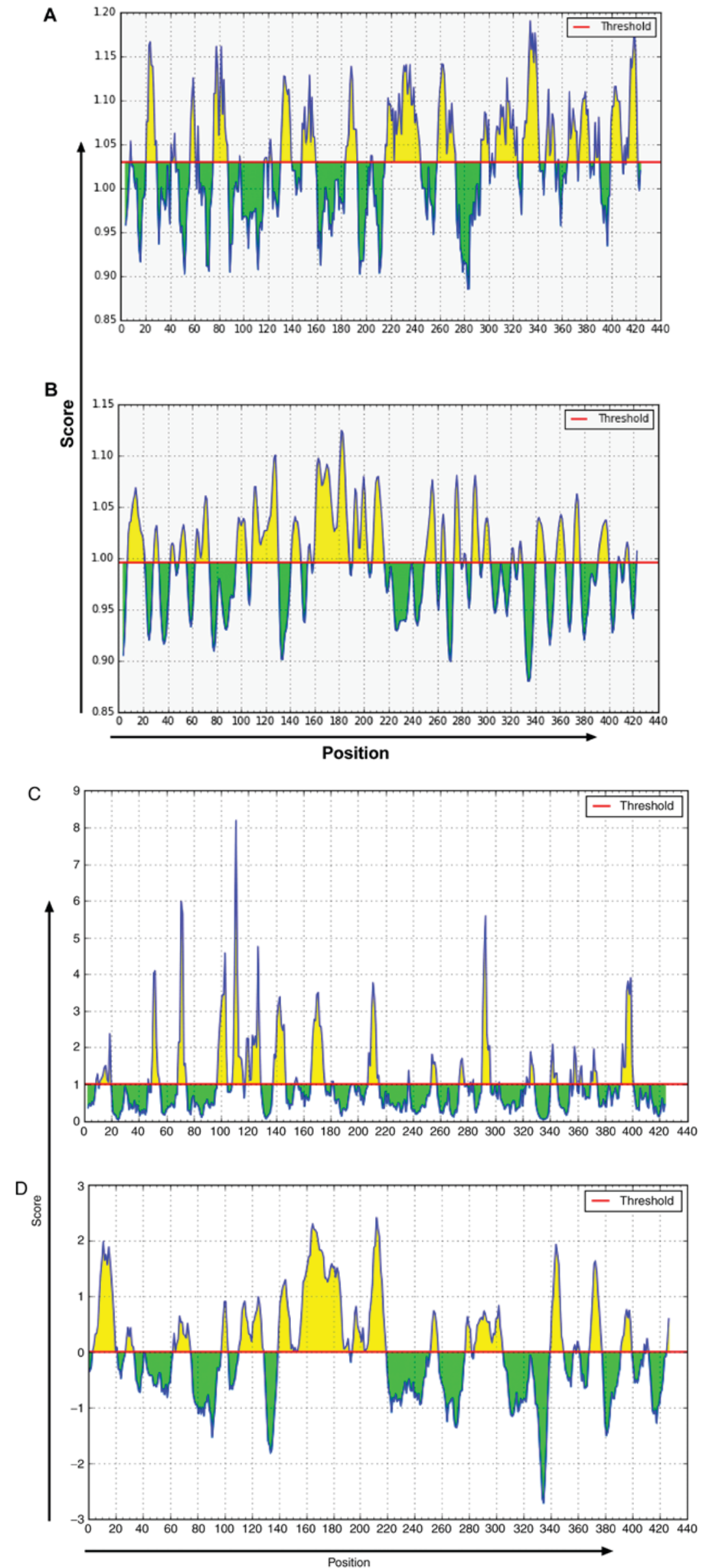

Figure 3. Prediction of vitamin D receptor B-cell epitopes by online software IEDB. (A) Prediction of antigenicity. (B) Prediction of flexibility of the region. (C) Prediction of surface accessibility. (D) Prediction of linear epitope. Yellow and green areas represent amino acid sequences that may form a B-cell epitope. 


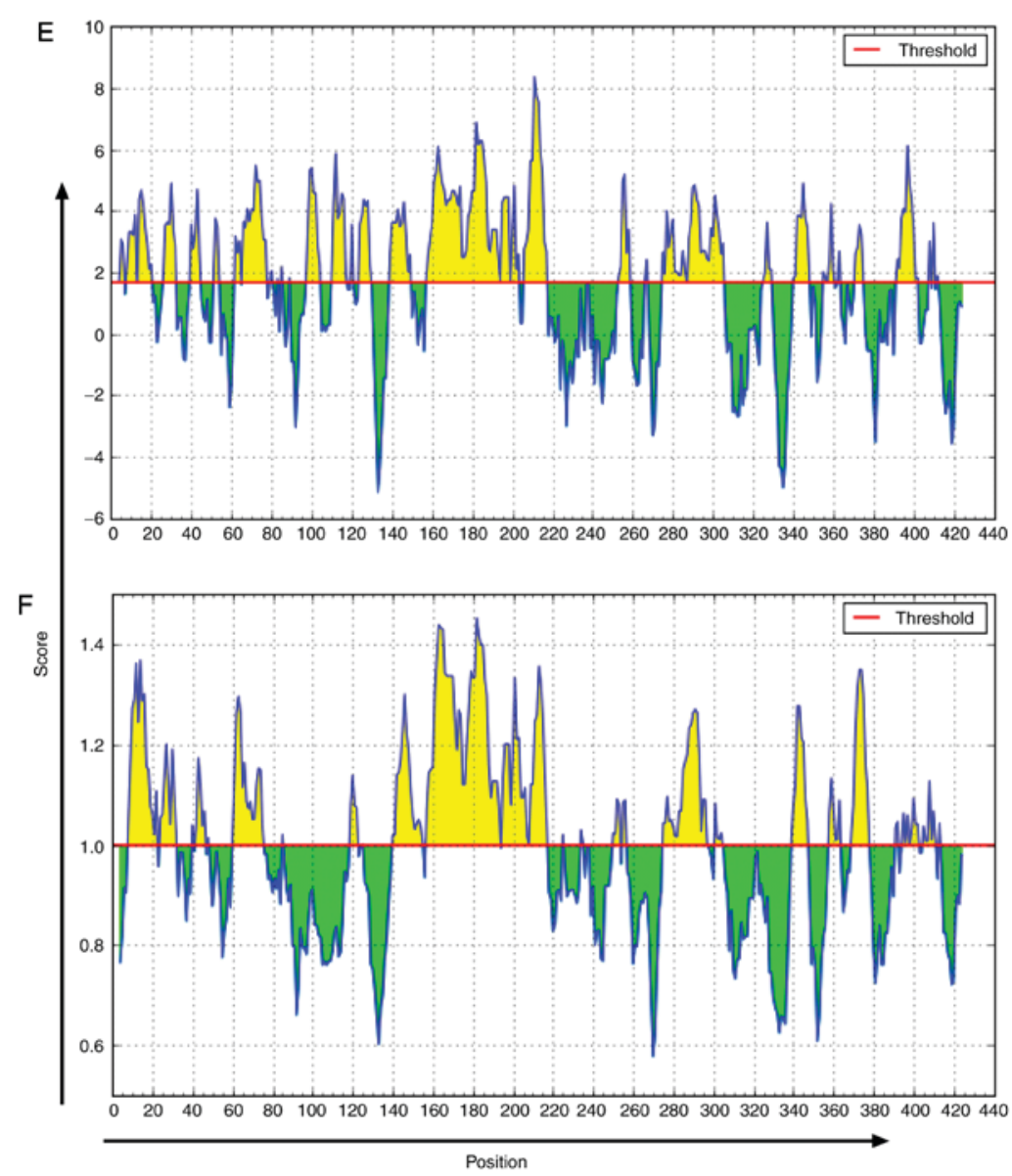

Figure 3. Continued. (E) Prediction of hydrophilicity. (F) Prediction of $\beta$ angle. Yellow and green areas represent amino acid sequences that may form a B-cell epitope. IEDB, immune epitope database.

histocompatibility complex (MHC) class I HLA-A0201 T-cell epitopes. This online prediction software gives the score of the amino acid sequence that may form the epitope, get 15 higher score of T-cell epitopes.

Prediction of tertiary structure of VDR. The tertiary structure of VDR was predicted using 3DLigandSite (16), a web server available at www.sbg.bio.ic.ac.uk/ 3dligandsite/. RasMol software (RasMol 2.7.5.2; www.rasmol.org/software/RasMol_2.7.5_ Manual.html) was used to analyze different models of the tertiary structure. The tertiary structure was displayed in the models of structure and group, in order to observe the three-dimensional structure of VDR molecules.

Statistical analysis. Statistical analysis was performed using SPSS 19.0 software (IBM Corp., Armonk, NY, USA). An independent samples t-test was used. Data are presented as the mean \pm standard deviation. $\mathrm{P}<0.05$ was considered to indicate a statistically significant difference.

\section{Results}

$V D R$ gene expression is decreased in children patients with asthma. RT-qPCR was used to detect VDR expression in the peripheral blood. VDR expression in the peripheral blood was significantly decreased in children patients with asthma compared with normal controls $(\mathrm{P}<0.05$; Fig. 1A).
Behavior of mice during excitation. During excitation, behavior of mice was observed. The mental state of mice was worsening, reduced activities, even gathering together and nodding (17) rapid and deep breathing, lip cyanosis, head and face itching, forelimb lifting and scratching the nose (17) dark gray hair and urinary or fecal incontinence. H\&E staining of the lung tissue revealed that there were a large number of inflammatory cells in and around the pulmonary bronchial vessels, in the pulmonary interstitium and pulmonary alveolar cavity. In addition, the structure of airway was disordered, and airway epithelial hyperplasia and hypertrophy were also observed. In the normal control group, lung tissue structure of the mice was clear, the respiratory epithelium was complete and a small number of inflammatory cells infiltrated (Fig. 1B).

VDR expression is decreased in the lungs of mouse models of asthma. RT-qPCR (Fig. 1C) and western blot assay (Fig. 1D), were performed to detect VDR expression in the lung tissue of mice. VDR expression in the lung tissue was significantly decreased in mice with asthma compared with normal control mice.

VDR gene-encoded amino acid sequences. According to the VDR protein provided in the GenBank, the sequence of 427 amino acids was as follows: MEAMAASTSLPDPG DFDRNVPRICGVCGDRATGFHFNAMTCEGCKGFFRRS MKRKALFTCPFNGDCRITKDNRRHCQACRLKRCVDI GMMKEFILTDEEVQRKREMILKRKEEEALKDSLRPK 

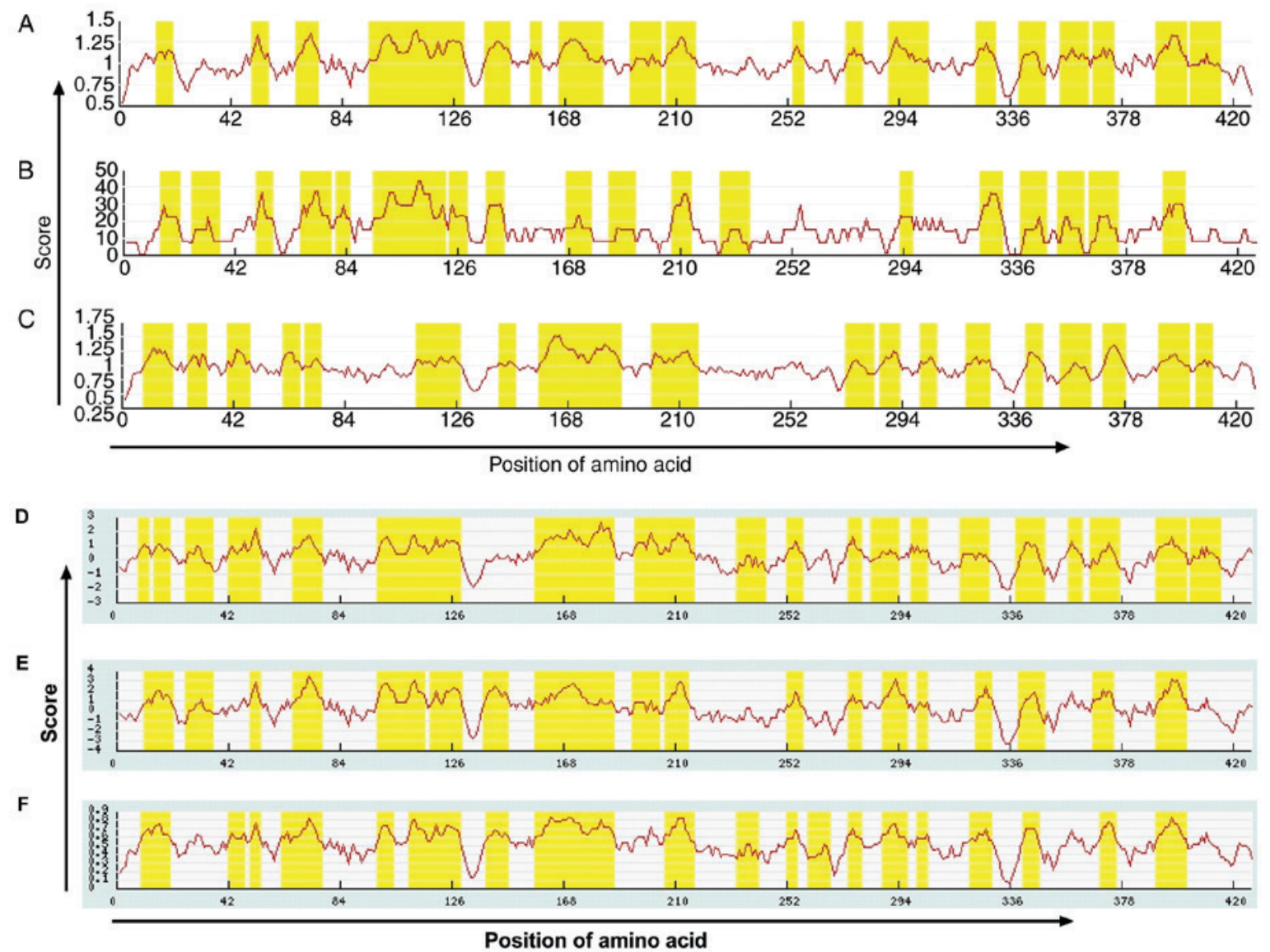

Figure 4. Prediction of VDR B-cell epitopes by online software LEPS. (A) Surface accessibility. (B) Polarity. (C) $\beta$ angle. (D) Flexibility of the region. (E) Prediction of the hydrophilcity. (F) Antigenicity. VDR, vitamin D receptor; LEPS, linear epitope prediction based on propensity scale and support vector machines.

\section{LSEEQQRIIAILLDAHHKTYDPTYSDFCQFRPPVRV NDGGGSHPSRPNSRHTPSFSGDSSSSCSDHCITSSD MMDSSSFSNLDLSEEDSDDPSVTLELSQLSMLPHLADL VSYSIQKVIGFAKMIPGFRDLTSEDQIVLLKSSAIEVIM LRSNESFTMDDMSWTCGNQDYK YRVSDVTKAGHS LELIEPLIKFQVGLK KLNLHEEEHVLLMICIVSPDRP GVQDAALIEAIQDRLSNTLQTYIRCRHPPPGSHLLYAK MIQKLADLRSLNEEHSKQYRCLSFQPESMKLTPLVLEV FGNEIS.}

Prediction of the secondary structure of the protein encoded by VDR gene. SOPMA was used to predict the secondary structure of VDR protein. Among all amino acids, the $\alpha$ helix accounted for $39.11 \%$ of the sequence, $\beta$-fold accounted for $8.67 \%$, irregular curl for $16.76 \%$ and the extended strand accounted for $15.46 \%$ (Fig. 2).

Prediction of VDR B-cell epitopes. The online prediction resources IEDB (Fig. 3) and LEPS (Fig. 4) together with hydrophilicity, antigenicity index, and flexibility parameters were used to predict B-cell epitopes. According to the prediction results, amino acid sequences were determined. A total of six VDR B-cell epitope areas were determined, including 37-45, 88-94, 123-131, 231-239, 286-294, 342-350 amino acid sequences.

Prediction of VDR T-cell epitopes. The online prediction resources SYFPEITHI and IEDB were used to predict
MHC class I HLA-A0201 T-cell epitopes (Table I). A total of $15 \mathrm{~T}$-cell antigen epitopes with high scores were selected. A total of three T-cell epitope areas with high scores were determined, including 125-130, 231-239, 265-272 amino acid sequences.

Display and analysis of tertiary structure of VDR gene. RasMol software was used to analyze the tertiary structure of 3DLigandSite-predicted VDR. The structure and group models were used to demonstrate the specific position of each amino acid on the three-dimensional structure (Fig. 5). The blue region of the structure and group models (Fig. 5B and C) was more distributed on the surface of spatial structure and was the potential binding portion of an antigen to antibody.

\section{Discussion}

Bronchial asthma is a chronic inflammatory airway disease with genetic susceptibility, involving a variety of inflammatory cells, inflammatory mediators and complex cytokine networks (18). This disorder is characterized by airway hyperresponsiveness and airway remodeling (19). Asthma is the most common chronic lung disease in China, that is a public health concern (20). The recurrent episodes of asthma can weaken pulmonary function, which negatively affects children's physical and mental health (21). Currently, glucocorticoid therapy is still the primary method of controlling asthma, 
Table I. SYFPEITHI and IEDB software predicted T-cell epitopes.

\begin{tabular}{llccccc}
\hline & \multicolumn{2}{c}{ SYFPEITHI software } & & \multicolumn{3}{c}{ IEDB software } \\
\cline { 1 - 1 } Initiation site & Amino acid sequence & Score & & Initiation site & Amino acid sequence & Score \\
\hline 378 & LLYAKMIQKL & 29 & & 96 & TDEEVQRKRE & 100 \\
350 & ALIEAIQDRL & 26 & & 68 & ITKDNRRHCQ & 99 \\
115 & ALKDSLRPKL & 25 & & 97 & DEEVQRKREM & 99 \\
232 & DLVSYSIQKV & 25 & & 396 & EHSKQYRCLS & 99.0 \\
261 & VLLKSSAIEV & 25 & & 156 & PVRVNDGGGS & 98.5 \\
225 & SMLPHLADLV & 24 & & 265 & SHPSRPNSRH & 98.5 \\
229 & HLKDNRRHCQ & 24 & & 167 & PSRPNSRHTP & 98.5 \\
254 & LTSEDQIVLL & 24 & & 180 & GDSSSSCSDH & 98.5 \\
324 & NLHEEEHVLL & 24 & & 231 & KDNRRHCQAC & 98 \\
354 & AIQDRLSNTL & 24 & & 120 & LRPKLSEEQQ & 98 \\
218 & TLELSQLSML & 23 & & 136 & LDAHHKTYDP & 98 \\
262 & LKSHPSRPNS & 23 & & 160 & NDGGGSHPSR & 98 \\
107 & ILKRKEEEHV & 22 & 64 & GDCRITKDNR & 97.5 \\
322 & KLNLHEEEHV & 22 & 66 & CRITKDNRRH & 97.5 \\
417 & LVLEVFGNEI & 21 & 155 & PPVRVNDGGG & 97.5 \\
\hline
\end{tabular}

A

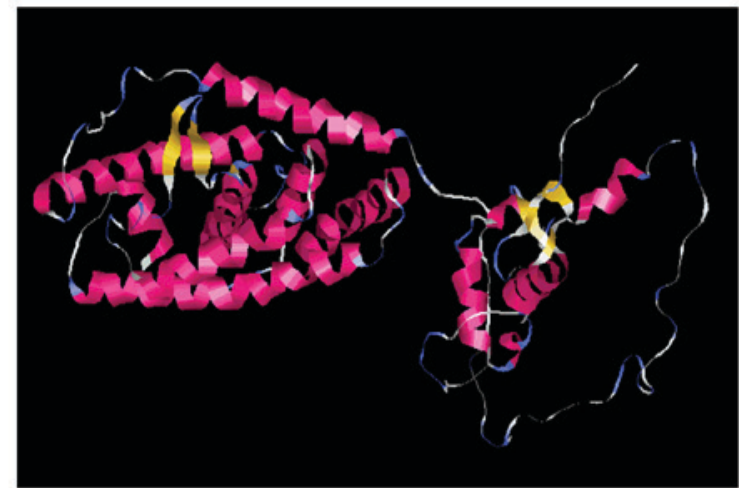

B

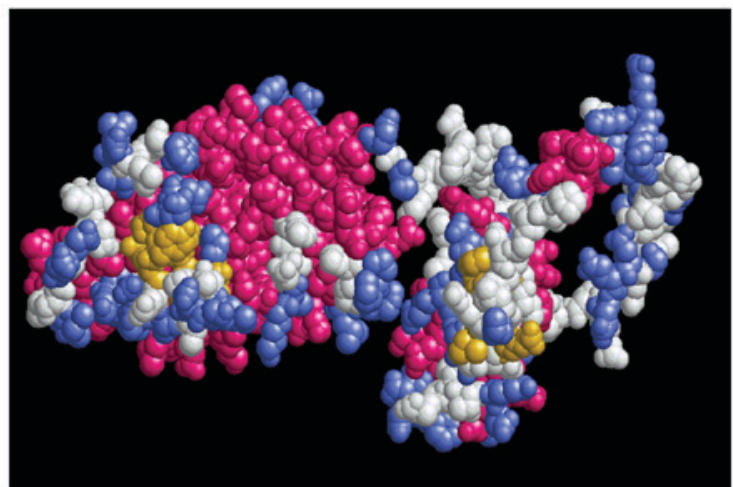

c

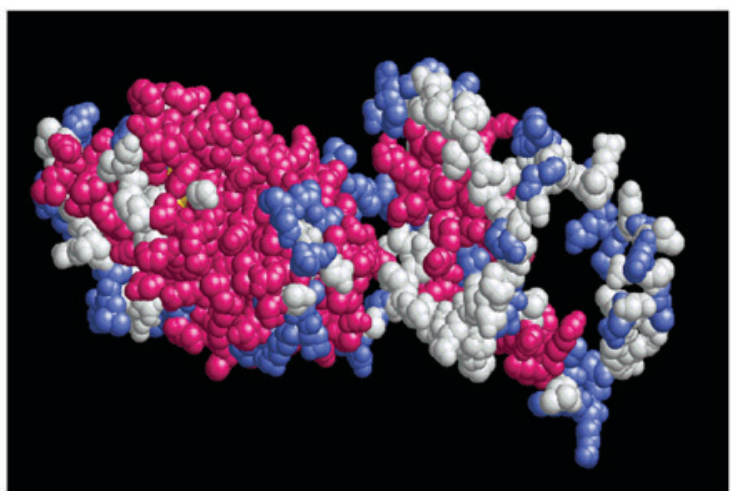

Figure 5. Tertiary structure of VDR predicted by online software 3DLigandSite. (A) Tertiary structure simulation model of VDR structure by 3DLigandSite. (B) Anterior view of the group structure. (C) Posterior view of the group structure. VDR, vitamin D receptor.

but glucocorticoid therapy often has serious complications to children affecting their development (22).

VDR is a member of steroid/thyroid hormone receptor superfamily. Human VDR is located on the long arm of chromosome 12 and it is expressed in numerous immune cells and immune tissues, including peripheral blood mononuclear cells, activated T and B cells, dendritic cells, thymus and lymph nodes (23). Following binding to VDR, vitamin D can mediate multiple biological effects including immunological regulation. Poon et al and Bossé et al performed a chromosome scan 
and proposed that VDR is a candidate gene associated with asthma $(24,25)$. In animal experiments, pulmonary inflammation and asthmatic symptoms were severe in C57/B6 mice, and in mice lacking VDR are resistant to airway inflammation (26). In the present study, peripheral blood samples were collected from asthmatic children and VDR expression was detected using RT-qPCR. The results demonstrated that VDR expression in peripheral blood was decreased in asthmatic children. A mouse model of asthma was also established in the present study and VDR expression was detected using western blot assay and RT-qPCR. Results demonstrated that VDR expression was significantly decreased. These results suggest that VDR may be involved in the progression of asthma.

Epitopes are antigenic molecules that determine the specificity of antigen-specific chemical groups, also known as antigenic determinants (27). Epitopes were initially identified in foot-and-mouth disease viruses (28). Epitopes are divided into conformational epitopes and linear epitopes based on their structure and they are also divided into B-cell epitopes and T-cell epitopes when present on different receptor-binding cells (29-32). Linear epitopes are primarily recognized by $\mathrm{T}$-cell antigen receptors and they are also recognized by B-cell antigen receptors, while conformational epitopes are only recognized by B-cell antigen receptors (30). Lin et al (33) used phage display technology to screen for immunodominant epitopes of leptospiral outer membrane proteins, which avoids the limitation that a single diagnostic antigen can be used to detect only a single serotype. The phage display technology possesses the advantage of early diagnostic value over other conventional detection methods. Mahajan et al (34) constructed polyvalent epitope vaccines with immunodominant B-cell and T-cell epitopes of liver and erythrocyte antigens to immunize mice, ultimately resulting in effective cellular and humoral immunity. In the present study, bioinformatics technique was used to predict VDR B-cell epitopes. It was determined that among all amino acids, $\alpha$ helix, $\beta$-fold, irregular curl and extended strand accounted for $39.11,8.67,36.77$ and $15.46 \%$ of the amino acid sequence, respectively. Potential VDR B-cell epitope areas included 37-45, 88-94, 123-131, 231-239, 286-294 and 342-350 amino acid sequences. SYFPEITHI and IEDB were used to predict HLA-A0201 T-cell epitopes and it was determined that 125-130 subset, 231-239 and 265-272 amino acid sequences exhibit high scores and may form T-cell epitopes.

In conclusion, prediction of the secondary and tertiary structures of VDR as well as the B-cell and T-cell epitopes to obtain highly scored amino acid sequences for establishing an efficient vaccine against asthma epitopes. Future studies should involve validation assays to support the results of the present study. These may involve synthesizing the VDR peptides identified in the present study for epitope-associated vaccine research. The future studies based on the present study may provide further data to be used for immunological diagnosis for asthma.

\section{Acknowledgements}

The present study was supported by the Liaoning Natural Fund Project (grant no. 2013021017) and Shenyang Science and Technology Plan Project (grant no. F15-139-9-35).

\section{References}

1. Vora AC: Bronchial asthma. J Assoc Physicians India 62 (3 Suppl): S5-S6, 2014.

2. Zhou $X$ and Hong J: Pediatric asthma management in china: Current and future challenges. Paediatr Drugs 20: 105-110, 2018

3. Kay AB: Mediators of hypersensitivity and inflammatory cells in the pathogenesis of bronchial asthma. Eur J Respir Dis Suppl 129: 1-44, 1983

4. Kuna P: Contemporary views on the pathological mechanism of asthma. Pol Merkur Lekarski 14: 519-521, 2003 (In Polish).

5. Carr TF and Peters AT: Chapter 12: Asthma: Principles of treatment. Allergy Asthma Proc 33 (Suppl 1): S39-S43, 2012.

6. Tang SP, Liu YL, Wang SB, Weng SF, Chen S, Zhang MJ, Dong L, Guo YH, Lin DR, Hua YH and Wang DY: Trends in prevalence and risk factors of childhood asthma in Fuzhou, a city in Southeastern China. J Asthma 52: 10-15, 2015

7. Huang H, Porpodis K, Zarogoulidis P, Domvri K, Giouleka P, Papaiwannou A, Primikyri S, Mylonaki E, Spyratos D, Hohenforst-Schmidt W, et al: Vitamin D in asthma and future perspectives. Drug Des Devel Ther 7: 1003-1013, 2013.

8. Anderson PH, Turner AG and Morris HA: Vitamin D actions to regulate calcium and skeletal homeostasis. Clin Biochem 45: 880-886, 2012

9. Myszka $\mathrm{M}$ and Klinger $\mathrm{M}$ : The immunomodulatory role of Vitamin D. Postepy Hig Med Dosw (Online) 68: 865-878, 2014 (In Polish).

10. Iruretagoyena M, Hirigoyen D, Naves R and Burgos PI: Immune response modulation by vitamin $\mathrm{D}$ : Role in systemic lupus erythematosus. Front Immunol 6: 513, 2015.

11. Mann EH, Chambers ES, Pfeffer PE and Hawrylowicz CM: Immunoregulatory mechanisms of vitamin D relevant to respiratory health and asthma. Ann N Y Acad Sci 1317: 57-69, 2014.

12. Karagün E, Ergin C, Baysak S, Erden G, Aktaş H and Ekiz Ö: The role of serum vitamin D levels in vitiligo. Postepy Dermatol Alergol 33: 300-302, 2016.

13. Abelha-Aleixo J, Fonseca R, Bernardo A, Mariz E and Costa L: Vitamin D - immunomodulatory actions and new potentialities. Acta Reumatol Port 39: 355-356, 2014.

14. Belorusova AY and Rochel N: Structural studies of vitamin D nuclear receptor ligand-binding properties. Vitam Horm 100: 83-116, 2016.

15. Duan Y, Learoyd J, Meliton AY, Clay BS, Leff AR and Zhu X: Inhibition of Pyk2 blocks airway inflammation and hyperresponsiveness in a mouse model of asthma. Am J Respir Cell Mol Biol 42: 491-497, 2010.

16. Wass MN, Kelley LA and Sternberg MJ: 3DLigandSite: Predicting ligand-binding sites using similar structures. Nucleic Acids Res 38 (Web Server Issue): W469-W473, 2010.

17. Haspeslagh E, Debeuf N, Hammad H and Lambrecht BN: Murine models of allergic asthma. Methods Mol Biol 1559: 121-136, 2017.

18. Balmasova IP, Sepiashvili RI, Sepiashvili IaR and Malova ES: Bronchial asthma pathogenesis and genetic prognosis development. Zh Mikrobiol Epidemiol Immunobiol 3: 60-67, 2014 (In Russian).

19. Cleary RA, Wang R, Wang T and Tang DD: Role of Abl in airway hyperresponsiveness and airway remodeling. Respir Res 14: 105, 2013.

20. Ladebauche P: Managing asthma: A growth and development approach. Pediatr Nurs 23: 37-44, 1997.

21. Tantisira KG, Litonjua AA, Weiss ST and Fuhlbrigge AL; Childhood Asthma Management Program Research Group: Association of body mass with pulmonary function in the Childhood Asthma Management Program (CAMP). Thorax 58: 1036-1041, 2003.

22. Grimfeld A, Just J and Bodart E: Role of inhalation therapy in the management of childhood asthma. Rev Mal Respir 9: 413-416, 1992 (In French).

23. Taymans SE, Pack S, Pak E, Orban Z, Barsony J, Zhuang Z and Stratakis CA: The human vitamin D receptor gene (VDR) is localized to region 12 cen-q12 by fluorescent in situ hybridization and radiation hybrid mapping: Genetic and physical VDR map. J Bone Miner Res 14: 1163-1166, 1999.

24. Poon AH, Gong L, Brasch-Andersen C, Litonjua AA, Raby BA, Hamid Q, Laprise C, Weiss ST, Altman RB and Klein TE: Very important pharmacogene summary for VDR. Pharmacogenet Genomics 22: 758-763, 2012. 
25. Bossé Y, Lemire M, Poon AH, Daley D, He JQ, Sandford A White JH, James AL, Musk AW, Palmer LJ, et al: Asthma and genes encoding components of the vitamin D pathway. Respir Res 10: 98, 2009.

26. Wittke A, Chang A, Froicu M, Harandi OF, Weaver V, August A, Paulson RF and Cantorna MT: Vitamin D receptor expression by the lung micro-environment is required for maximal induction of lung inflammation. Arch Biochem Biophys 460: 306-313, 2007.

27. Hruby S, Alvord EC Jr, Martenson RE, Deibler GE, Hickey WF and Gonatas NK: Epitopes in myelin basic protein reactive with monoclonal antibodies. Prog Clin Biol Res 146: 271-276, 1984.

28. Ma X, Li P, Sun P, Bai X, Bao H, Lu Z, Fu Y, Cao Y, Li D, Chen Y, et al: Construction and characterization of $3 \mathrm{~A}$-epitope-tagged foot-and-mouth disease virus. Infect Genet Evol 31: 17-24, 2015.

29. Augustin T, Cehlar O, Skrabana R, Majerova P and Hanes J: Unravelling viral camouflage: Approaches to the study and characterization of conformational epitopes. Acta Virol 59: 103-116, 2015.

30. Forsström B, Axnäs BB, Rockberg J, Danielsson H, Bohlin A and Uhlen M: Dissecting antibodies with regards to linear and conformational epitopes. PLoS One 10: e0121673, 2015.
31. Pinilla C,Appel JR, Judkowski V and Houghten RA: Identification of B cell and T cell epitopes using synthetic peptide combinatorial libraries. Curr Protoc Immunol Chapter 9: Unit9.5, 2012.

32. Amin MR, Siddiqui MS, Ahmed D, Ahmed F and Hossain A: Band T-cell epitope mapping of human sapovirus capsid protein: an immunomics approach. Int J Bioinform Res Appl 7: 287-298, 2011.

33. Lin X, Chen Y and Yan J: Recombinant multiepitope protein for diagnosis of leptospirosis. Clin Vaccine Immunol 15: 1711-1714, 2008.

34. Mahajan B, Berzofsky JA, Boykins RA, Majam V, Zheng H, Chattopadhyay R, de la Vega P, Moch JK, Haynes JD, Belyakov IM, et al: Multiple antigen peptide vaccines against Plasmodium falciparum malaria. Infect Immun 78: 4613-4624, 2010.

This work is licensed under a Creative Commons Attribution-NonCommercial-NoDerivatives 4.0 International (CC BY-NC-ND 4.0) License. 